\title{
Associations between perceived cooking ability, dietary intake and meal patterns among older women
}

\author{
Kerstin Gustafsson', Jenny Andersson², Ingegerd Andersson', Margaretha Nydahl2, \\ Per-Olow Sjödén' and Birgitta Sidenvall'
}

Departments of 'Public Health and Caring Sciences, and 2Domestic Sciences, Uppsala University, Sweden

Abstract

Background: Problems related to cooking ability are likely to develop with increasing disability in women with stroke, Parkinson's disease and rheumatoid arthritis.

Objective: The aim of this study was investigate the extent to which dietary intake and meal patterns covary with the perceived ability to cook among women with or without these diagnoses.

Design: Data on food intake were collected using two $24 \mathrm{~h}$ recalls for 69 community-dwelling non-disabled women as well as women with the specified diseases, aged 64-88 years, cohabiting or living alone. The participants were divided into three groups based on their perceived ability to cook: cooking group $(n=24)$, part-cooking group $(n=31)$ and no-cooking group $(n=14)$.

Results: Reported energy intake was below reference values in all three groups, but tended to be lower for the part-cooking and no-cooking groups. Reported intake of vitamin D and dietary fibre was low in all three groups, as was calcium intake in the part-cooking and no-cooking groups. However, nutrient density was mostly satisfactory. The energy content of hot meals was lowest for the part-cooking group.

Conclusions: Hot meals contributed substantially to the daily energy intake in all groups, but the contents of protein and carbohydrate of meals were lower for the part-cooking and no-cooking groups. Hot meals need to be complemented by nutritious snacks.

Keywords: Disability, energy and dietary intake, meals, older women.

Received: September 11, 2001. Revisions: December 12, 2001. January 14, 2002. Accepted January 23,2002

\section{Introduction}

Old age (defined in this study as $>65$ years) and restricted mobility seem to result in cooking problems which may influence energy intake (1). As long as old people living at home are healthy, they appear to have adequate eating habits (2). However, a Swedish study revealed a reduction in the number of meals after retirement (3). In a study focusing on protein and energy status at hospital admission, $28.5 \%$ of the older patients were malnourished (4). Thus, when health problems occur in old people living at home, this increases their risk for poor nutrition. Among frail people, there is also a decline in energy intake, which is associated with the consumption of smaller portions, a slower rate of eating and fewer snacks between meals (5).

Parkinson's disease (PD) and rheumatoid arthritis (RA) are accompanied by physical disability and problems in the meal situation $(6,7)$. Such problems also occur among people afflicted by stroke (8). Wylie et al. (1) concluded that restricted mobility in older people has a detrimental influence on their ability to buy and prepare cooked meals. However, independence is highly valued among old people and it is important for women to cook by themselves (9). Among old people, a proper meal is considered equal to a cooked meal with potatoes, meat and vegetables, often served with gravy (9). Hot meals contribute a considerable part of the daily energy and nutrient intake (10), and a regular pattern of warm meals increases the possibility of a nourishing diet (11).

Thus, it is of interest to study how the perceived declining ability to cook (Gustafsson et al., in press) is related to the frequency and composition of women's own meals, above all cooked meals. Are these meals of major importance for their daily energy intake, or do other eating events compensate 
for possible deficiencies? The aim of the present study was to investigate the extent to which dietary intake as well as meal patterns covary with perceived ability to cook among older women.

\section{Subjects and methods}

\section{Part I}

In part 1 of the project "Meals, Eating habits and Nutrient intake among Elderly Women" (the MENEW project), data collection was carried out by home visits during 1997-1998. A random sample of 570 women was drawn from the official register of the Swedish population in Uppsala, Enköping and Sala municipalities, covering both urban and rural areas. The sample was stratified for age, living alone or cohabiting. The women were invited by letter, and since 65 of them could not be reached by telephone, which was necessary for inclusion (see below), the study population comprised 505 women. Another 106 were excluded because they did not fulfil the inclusion criteria. In addition to age and living conditions, the inclusion criteria were: retired, self-managing in food-related work, able to carry on a conversation and free from severe diseases (see below). In total, 240 declined to participate. The inclusion procedure, reasons for exclusion and dropout have been described elsewhere (12). The main reasons for not participating was lack of time, tiredness or illness. Thus, a total of 159 non-disabled community-dwelling women was included successively to fill groups of women aged 64-68 years, $74-78$ years and $84-88$ years, half living alone and half with somebody else. The inclusion rate for the whole sample was $40 \%$ (Table 1). The women reported data on dietary and nutrient intake, and half of them also participated in qualitative interviews. The present paper studied 17 of these women.
Letters were sent by mail with information about the study to women who met the inclusion criteria. One week later, they were contacted by telephone and participation was discussed. Questions were asked about self-management in food-related work, and whether the woman had a diagnosis of PD, RA or stroke. This dialogue also assessed each woman's orientation with respect to time, place and person.

\section{Part 2}

In part 2 of the MENEW project, women diagnosed with PD, RA or stroke were included. In total, 73 women participated in this part in 1998-1999, and the same data collection methods as in part 1 were used. The women who were 64-88 years old and who lived alone or cohabited were selected consecutively from medical registers covering Uppland, a county in the central part of Sweden. Inclusion criteria were (i) diagnosis, (ii) age, (iii) living at home, and (iv) ability to carry on a conversation. The inclusion proceeded until equally large groups of women were recruited with respect to diagnosis, age, living with someone $(50 \%)$ or living alone $(50 \%)$. Data on invited, excluded, declining and included women are shown in Table 1.

Researchers from the project group included women with stroke and PD, and a research nurse helped with inclusion of the RA group. She telephoned presumptive participants identified in the patient register of the Rheumatological Clinic of the Akademiska Hospital in Uppsala to ask for permission for further contact. Women with more than one of these diagnoses, other severe diseases and dementia were excluded (Table 1).

The women in part 2 of the project who met the inclusion criteria were also asked about participation by letter. Based on a telephone call 1 week after they received the letter, women with other diseases

Table I. Number of participants invited, excluded and declining in parts I and 2 of the MENEW project (Meals, Eating habits and Nutrient intake among Elderly Women) and the number of women included in this study

\begin{tabular}{|c|c|c|c|c|}
\hline & Not disabled & Stroke & Parkinson's disease & Rheumatoid arthritis \\
\hline Invited & 505 & 60 & 43 & 70 \\
\hline Excluded & 106 & 18 & 4 & 1 \\
\hline Declining & 240 & 18 & 15 & 44 \\
\hline Included in this study & $17^{\mathrm{a}}$ & $17^{\mathrm{b}}$ & $17^{b}$ & $18^{\mathrm{b}}$ \\
\hline
\end{tabular}

a Selected women willing to talk about food habits, food-related health and attitudes towards the meal assistance.

b Women who had two $24 \mathrm{~h}$ food intake recalls and a qualitative interview. 
or speech difficulties were excluded. All women had the opportunity to decline participation. Reasons for non-participation were mostly tiredness or self-reported serious illness. A total of 73 women accepted, and the inclusion rate was $57 \%$ for stroke, $62 \%$ for PD and $36 \%$ for RA. Seventy-five per cent of the women, i.e. 54, were interviewed. Twenty-four hour recalls (see below) were missing for two women.

\section{The present sample}

In part 1 of the project, 18 non-disabled women were selected strategically for the study sample with equal representation of age groups and living conditions (alone/with somebody). When the researcher visited them these women stated a willingness to talk about food habits, food-related health and attitudes towards meal assistance, which was judged to be necessary for interview participation. One $24 \mathrm{~h}$ recall (see below) was missing for one woman, who was excluded. Thus, the present study was based on data from 17 women from part 1 and 52 disabled women from part 2, giving a total of 69 women. This sample, and an additional three women, also participated in a qualitative study of perceived cooking ability and the cultural meaning of accomplishing food-related work (Gustafsson et al., in press). The same sample participated in the present study, now focusing on dietary intake.

\section{Data collection}

\section{Food intake}

Data on food intake and meal patterns are based on two $24 \mathrm{~h}$ recalls according to a standardized interview technique (13). Non-disabled women were visited for the first interview and the second was performed by telephone. The women in part 2 were visited twice. Thus, data from personal (first) interviews were compared with those from telephone (second) interviews. Each woman described in as much detail as possible what she had been eating and drinking on the day before the interview, starting with what was the first consumed that day, at what time, and where the eating/drinking took place. Quantities and portion sizes were estimated by household measures and by "The Meal Model", a picture book from the Swedish National Food Administration showing several portion sizes for a variety of foods and dishes. Recipes and cooking methods used on these days were also recorded. As it may be difficult to remember which food items had been eaten, a checklist was prepared for this study to map the intake of, e.g. sweets, biscuits and drinks. The women were visited during weekdays, and the $24 \mathrm{~h}$ recalls therefore covered food intakes on these days and on Sundays. Thus, no Fridays or Saturdays are represented in the food intake data for the present study. Data were also collected by a 3 day self-report food diary, covering Fridays and Sundays. However, some women with serious disability were unable to complete these, and therefore the obtained data were excluded. Data from the food dairies have been reported elsewhere (Andersson et al., in press; Nydahl et al., in press).

\section{Height and body weight}

At one visit, height and body weight were measured with standardized tools. The height of each subject was measured to the nearest $0.5 \mathrm{~cm}$. Body weight was recorded to the nearest $0.5 \mathrm{~kg}$ using an EKS digital weighing scale. Measures were taken without shoes but with thin clothes for the calculation of body mass index (BMI) and estimation of basal metabolic rate $\left(\mathrm{BMR}_{\text {est }}\right)$, calculated according to the Nordic Nutrition Recommendations (NNR) (14).

\section{Qualitative interviews}

The interviews had an ethnographic approach. They were conducted in the women's home and concerned their experiences. The interviews were based on an interview guide with open-ended questions covering family situation, food-related work and meal situation. For women suffering from a disease, duration and symptoms were discussed, as well as how these influenced food-related work and how problems were handled. Field notes were taken concerning the condition of the women and their functioning in the home, based on a visual assessment by each interviewer. The interviews lasted for 30-90 min and were tape-recorded. Supplementary questions were asked at a second visit and unclear points were checked and sorted out. For women in part 1 of the project this was done by telephone.

\section{Categorization}

Based on the qualitative interviews and the field notes, the women were classified into three groups according to their ability to cook their principal meals.

- Cooking group: cooking with fresh ingredients. There was limited use of pre-prepared food items. 
- Part-cooking group: part cooking due to disability or frailty. Cooking was simplified by the use of pre-prepared foods, convenience foods (ready-made meals for reheating) and aids. Some of the women had husbands or other relatives who helped them to cook.

- No-cooking group: no own cooking. Their husbands had taken over, convenience foods were bought or "Meals on Wheels" was used.

The first author carried out the categorization after reading all interviews. Independent categorization was also done by the researcher who had done the interview, and who had more information about the woman's situation in field notes. The interviews that were performed by the first author were also categorized by others in the research group. Some uncertain cases were discussed, adding more information about them. Interrater reliability was calculated as the number of agreements/number of agreements + disagreements.

\section{Data analyses}

Trained dieticians and nurses coded the food intake data using portion sizes and weights estimated by the women. When weights and portion sizes were missing, standardized weights or portion sizes were used according to a weight table (15). The database "PC-kost" (Version 2, 1999) was used. This contains 1600 food items, and if a food item was missing, a similar one was coded. Intake of energy, energy-yielding nutrients and selected nutrients were calculated using the MAT's nutrient calculation system (Version 4.05, 1999).

Eating events were then classified in the following categories: hot breakfast, cold breakfast, hot meals and other eating events. The special focus on a hot breakfast and hot meals was guided by an interest in studying cooking ability. In the present study, a hot meal means a cooked meal. Among older people this is almost always a "proper dinner" (9), but in this study, it could also be, e.g. a boiled rice pudding for an evening meal. A hot breakfast included porridge or gruel, while a cold breakfast contained sour milk or just an open sandwich with coffee or tea. Remaining eating events were classified as "other", which included snacks, but also meals that were not cooked. Such a meal could be a rose-hip soup and an open sandwich for lunch.

The three groups of women were compared by the Kruskal-Wallis non-parametric analysis of variance. This method was chosen since the groups
Table 2. Age, body weight, body mass index (BMI) and reported energy intake/estimated basal metabolic rate $\left(\mathrm{El}_{\text {rep }} / \mathrm{BMR}_{\text {est }}\right)($ mean $\pm \mathrm{SD})$; health status and diagnosis of the three groups of cooking performance

\begin{tabular}{|c|c|c|c|}
\hline & Cooking group & $\begin{array}{l}\text { Part-cooking } \\
\text { group }\end{array}$ & No-cooking group \\
\hline Age $\left(\right.$ years) ${ }^{\mathrm{a}}$ & $74.7 \pm 8.1$ & $73.8 \pm 6$ & $75.9 \pm 6.6$ \\
\hline Body weight $(\mathrm{kg})^{\mathrm{a}}$ & $68.3 \pm 10.3^{b}$ & $64.0 \pm 10.8^{b}$ & $64.6 \pm 16.1^{c}$ \\
\hline $\mathrm{BMI}\left(\mathrm{kg} / \mathrm{m}^{2}\right)$ & $26.5 \pm 3.8^{b}$ & $24.5 \pm 3.1^{b}$ & $26 \pm 4^{c}$ \\
\hline $\mathrm{El}_{\text {rep }} / \mathrm{BMR}$ est & $1.27 \pm 0.37^{b}$ & $1.13 \pm 0.32^{b}$ & $1.3 \pm 0.39^{c}$ \\
\hline Not disabled (n) & 15 & 2 & - \\
\hline Stroke (n) & 5 & 7 & 5 \\
\hline $\begin{array}{l}\text { Parkinson's } \\
\text { disease (n) }\end{array}$ & 3 & 6 & 8 \\
\hline $\begin{array}{l}\text { Rheumatoid } \\
\text { arthritis (n) }\end{array}$ & । & 16 & । \\
\hline Total (n) & 24 & 31 & 14 \\
\hline
\end{tabular}

differed with respect to data distributions. Posttests, i.e. multiple comparisons between groups, were performed only when a significant overall difference was obtained. Means and standard deviations (SD) were used for descriptive purposes. As a reference, the 3rd edition of The Swedish Nutrition Recommendations (SNR) (16) was used for energy-yielding nutrients and intake of selected nutrients as well as nutrient density with values calculated for individuals $>75$ years. Reference values for energy were estimated by calculating BMR (14) and by setting the physical activity level (PAL, i.e. total energy expenditure divided by basal metabolic rate) to 1.6 for the cooking group, 1.4 for the part-cooking group and 1.3 for the no-cooking group $(14,17)$. The PAL estimations were based on the knowledge from the women in the qualitative interviews. Paired $t$-tests were used for comparisons between the first and the second $24 \mathrm{~h}$ recall, and unpaired $t$-tests for comparisons between meal types. The analyses were performed with the statistical software package Statview, Version 5.0. The Research Ethics Committee of the Faculty of Medicine, Uppsala University, approved the study.

\section{Results}

There were no significant differences in energy intake between the $24 \mathrm{~h}$ recalls performed in the women's homes and those performed as telephone interviews among the women in part 1 of the project. The total numbers of women in the different categories were 24 in the cooking group, 31 in 
the part-cooking group and 14 in the no-cooking group. Interrater reliability for this categorization was calculated as $65 / 65+4$, i.e. $94 \%$. Characteristics of women in the three groups are shown in Table 2.

\section{Intakes of energy, selected nutrients and dietary \\ fibre}

Mean energy intake was 6.9 MJ (1646 kcal) in the cooking group, $5.9 \mathrm{MJ}(1406 \mathrm{kcal})$ in the part-cooking group and $6.3 \mathrm{MJ}(1494 \mathrm{kcal})$ in the no-cooking group, and there were no significant between-group differences. Energy intakes in all three groups were lower than the reference value (14), i.e. $8.8 \mathrm{MJ}(2103$ $\mathrm{kcal})$ for the cooking group, 7.4 MJ (1769 kcal) for the part-cooking group and 6.9 MJ (1649 kcal) for the no-cooking group (Table 3 ). The reported energy intake/estimated basal metabolic rate $\left(\mathrm{EI}_{\text {rep }} /\right.$ $\mathrm{BMR}_{\text {est }}$ ) was 1.27 for the cooking group, 1.13 for the part-cooking group and 1.3 for the no-cooking group (Table 2). A cut-off value for $\mathrm{EI}_{\text {rep }} / \mathrm{BMR}_{\text {est }}$ was not used. Thus, all women were included in this analysis.

The reported intakes of energy-yielding nutrients, calculated as a percentage of the total energy intake, did not differ significantly between the groups (Table 3). However, carbohydrate intake was lower, while fat and protein intakes were higher than recommended reference values in all three groups (16), with no significant difference between them.

Table 3. Energy-yielding nutrients in grams and energy per cent (E\%), and intake of selected nutrients and dietary fibre in grams and nutrient density (per MJ) in the cooking, part-cooking and no-cooking groups and the Swedish Nutrition Recommendations (SNR)

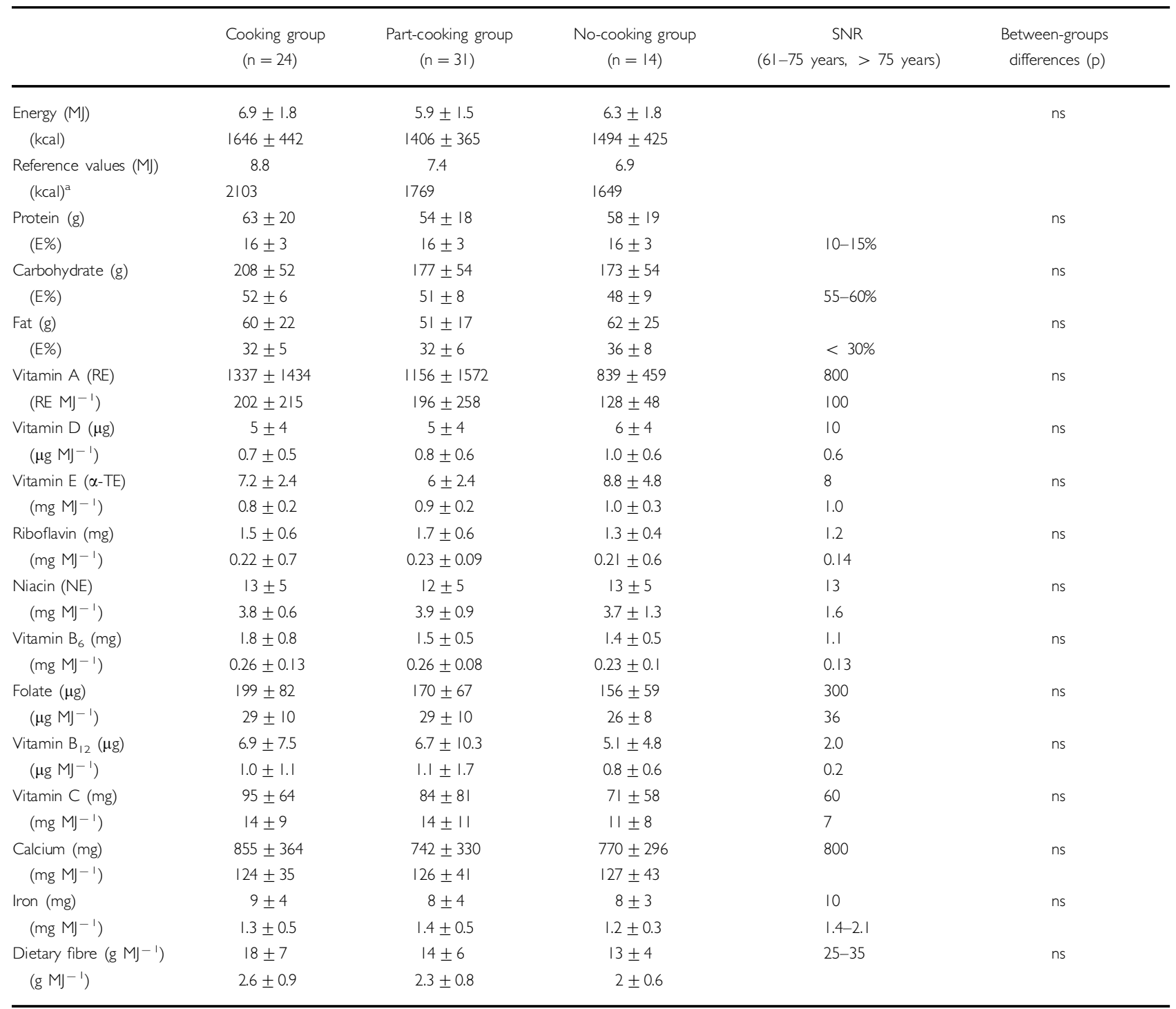


Table 4. Mean number of eating events (Ee) on two non-consecutive days and the distribution of percentage energy intake (E\%) from these meals in the three groups

\begin{tabular}{|c|c|c|c|c|c|c|c|}
\hline Meal type & $\mathrm{Ee}$ & $E \%$ & $\mathrm{Ee}$ & $E \%$ & $\mathrm{Ee}$ & $E \%$ & $p$ \\
\hline Hot breakfast & 0.3 & 6 & 0.2 & 5 & 0.3 & 7 & ns \\
\hline Cold breakfast & 0.7 & 14 & 0.9 & 15 & 0.6 & 15 & ns \\
\hline Hot meal & 1.3 & 43 & 1.3 & 45 & 1.2 & 39 & ns \\
\hline
\end{tabular}

Folate, iron and dietary fibre intakes were below recommended levels in all three groups, as was the intake of vitamin D. Vitamin E was below recommended level in the cooking and part-cooking groups. Further, calcium intake was below the recommended level in the part-cooking and nocooking groups. Mean intakes of vitamin $\mathrm{B}_{6}, \mathrm{~B}_{12}$ and $\mathrm{C}$ were above recommended levels in all groups. Nutrient density was satisfactory except for folate in all groups, and slightly below recommended for vitamin $\mathrm{E}$ in the cooking and part-cooking groups. Iron was slightly below the recommended level for the cooking and no-cooking groups (Table 3).

\section{Meal patterns}

The mean number of eating events per day did not differ between the groups (5.4, 5.2 and 5.1). In all groups, cold breakfast meals were consumed more frequently than were hot breakfasts. The frequency of hot meals was almost the same, and such meals contributed $43 \%$ of the daily energy intake for the cooking group, $45 \%$ for the part-cooking group and $39 \%$ for the no-cooking group (Table 4). Other eating events contributed $37 \%$ of the daily energy intake for the cooking group, $35 \%$ for the partcooking group and 39\% for the no-cooking group.

In the whole group, the mean energy content of hot breakfast meals was $151 \mathrm{~kJ}(360 \mathrm{kcal})$ and that for cold breakfast meals $126 \mathrm{~kJ}$ (300 kcal). An average hot meal contributed one-third of the daily energy intake (cooking group 35\%, part-cooking group 33\%, no-cooking group 33\%). Reported mean energy in a hot meal differed significantly between the groups [cooking group $238 \mathrm{~kJ}$ (568 kcal), part-cooking group $194 \mathrm{~kJ}$ (465 kcal), nocooking group $205 \mathrm{~kJ}$ (489 kcal)]. Other eating occasions tended to have non-significantly lower energy contents in the part-cooking group compared with the other groups (Table 5).

Hot meals differed significantly in protein and carbohydrate content between the groups. The cooking group had the highest hot meal content of protein, carbohydrate and fat. The protein content of hot meals was lowest in the part-cooking group, and carbohydrate content was higher in the cooking group. The fat content of the meals did not differ significantly between groups (Table 6).

\section{Discussion}

\section{Nutrient intake and cooking ability}

The results indicate that perceived cooking ability covaried with energy and nutrient intake as well as

Table 5. Energy contents $(\mathrm{kJ}$ and $\mathrm{kcal}$ ) presented as mean $\pm \mathrm{SD}$ according to meal types in the three groups

\begin{tabular}{|c|c|c|c|c|}
\hline Meal type & $\begin{array}{l}\text { Cooking group } \\
\qquad(n=24)\end{array}$ & $\begin{array}{l}\text { Part-cooking group } \\
\qquad(n=31)\end{array}$ & $\begin{array}{l}\text { No-cooking group } \\
\qquad(n=14)\end{array}$ & $p$ \\
\hline $\begin{array}{l}\text { Hot breakfast (kJ) } \\
\qquad(\text { kcal) }\end{array}$ & $\begin{array}{l}152 \pm 81 \\
364 \pm 195\end{array}$ & $\begin{array}{l}153 \pm 82 \\
366 \pm 197\end{array}$ & $\begin{array}{l}165 \pm 72 \\
394 \pm 173\end{array}$ & ns \\
\hline $\begin{array}{l}\text { Cold breakfast (kJ) } \\
\qquad(\text { kcal) }\end{array}$ & $\begin{array}{l}135 \pm 63 \\
323 \pm|5|\end{array}$ & $\begin{array}{l}113 \pm 66 \\
271 \pm 158\end{array}$ & $\begin{array}{l}140 \pm 68 \\
335 \pm 163\end{array}$ & ns \\
\hline $\begin{array}{l}\text { Hot meals (kJ) } \\
\qquad(\text { kcal) }\end{array}$ & $\begin{array}{l}238 \pm 99 \\
568 \pm 237\end{array}$ & $\begin{array}{l}194 \pm 118 \\
465 \pm 283\end{array}$ & $\begin{array}{l}205 \pm 85 \\
489 \pm 202\end{array}$ & $<0.05^{a}$ \\
\hline $\begin{array}{l}\text { Other eating events (kJ) } \\
\quad(\mathrm{kcal})\end{array}$ & $\begin{array}{c}82 \pm 73 \\
198 \pm 175\end{array}$ & $\begin{array}{c}74 \pm 62 \\
177 \pm 149\end{array}$ & $\begin{array}{c}82 \pm 67 \\
196 \pm 161\end{array}$ & ns \\
\hline
\end{tabular}

${ }^{a}$ Kruskal-Wallis analysis of variance, showing differences between all three groups. 
with meal pattern. Women with perceived disability in food-related work tended to have a lower energy intake than women without such disability (Table 3). In the long run, a lower energy intake may have consequences for the nutritional status of these women. The cooking and part-cooking groups reported energy intakes lower than reference values as calculated from estimated BMR and PAL for each group, whereas the no-cooking group was similar to the used PAL (Table 3). The low $\mathrm{EI}_{\text {rep }} / \mathrm{BMR}_{\text {est }}$ quotient suggests possible underreporting (Table 2), which will be discussed below. The energy percentage for protein was satisfactory and slightly above recommendations in all groups, as was also true for the energy percentage for fat (Table 3). This is in line with what has been suggested for chronically ill groups at risk for malnutrition (5). However, the mean intake of carbohydrates was below recommendations (SNR). In view of the low energy intake, meals should be complemented with bread, and more potatoes and rice should be included in hot meals.

Low intakes of vitamins and minerals are likely to accompany low energy intakes (18), as also seen in the present study (Table 3). Low intakes of vitamin D in all groups have also been reported in another study of older people (19). Osteoporosis is an increasing problem among older women (20) and has been associated with, among other things, a low intake of vitamin D. If intake is low, women should be recommended supplementation with vitamin D (SNR). Calcium intake was below the recommendations for the part-cooking and the nocooking groups. An increased intake of diary products should be recommended for these groups.

\section{Hot meals should be complemented by snacks}

The number of eating events did not differ significantly between groups, although there was a slight trend towards fewer eating events with an increased cooking disability (Table 4). Hot meals were consumed with nearly the same frequency in all three groups. However, in the part-cooking group, they tended to contribute more to the energy intake per day than in the no-cooking group. At the same time, the part-cooking group also tended to have a lower frequency of "other eating events", which also contributed less to their daily energy intake. A recommendation to old people who have difficulties in eating large meals is to have more nourishing snacks between meals (5). This recommendation may have been taken up by women in the no-cooking group, who reported "other eating events" to a greater extent. Such events contributed more to their daily energy intake than in the partcooking group.

The hot meal had a slightly lower energy content in the part-cooking group than in the other groups (Table 5). This was due to significantly lower contents of protein and carbohydrates (Table 6). The fat content was also lower, although not significantly so, in hot meals in this group than in the other groups. The part-cooking group had a higher frequency of breakfasts than the no-cooking group, and a lower frequency of hot breakfasts, but did not have fewer meal occasions than the no-cooking group. However, women who struggled with their meals in the part-cooking group may have simplified their cooking by making a cold, and often less nourishing breakfast. In the no-cooking group, hot breakfasts had a higher energy content compared with the other groups. Thus, when somebody cooked for them, disabled women appeared to eat more nourishing breakfasts. Older disabled women may be more vulnerable than men when they can no longer manage their cooking, since it is the woman's field of competence that has been affected. A declining cooking ability in a man may not be as decisive if he has a wife who can cook for him.

Table 6. Protein, fat and carbohydrate content in grams (mean $\pm \mathrm{SD}$ ) in hot meals and the percentage of total daily intakes from each nutrient in the three groups

\begin{tabular}{|c|c|c|c|c|}
\hline $\begin{array}{l}\text { Carbohydrate (g) } \\
\text { (\% of daily carbohydrate intake) }\end{array}$ & $\begin{array}{l}62 \pm 28^{\mathrm{a}} \\
30\end{array}$ & $\begin{array}{l}49 \pm 28^{b} \\
28\end{array}$ & $\begin{array}{l}48 \pm 29^{\mathrm{a}} \\
28\end{array}$ & $<0.01$ \\
\hline
\end{tabular}

a,b Means with different superscript letters differ significantly. 
Table 6. Protein, fat and carbohydrate content in grams (mean \pm SD) in hot meals and the percentage of total daily intakes from each nutrient in the three groups

\begin{tabular}{|c|c|c|c|c|}
\hline (\% of daily protein intake) & 43 & 40 & 43 & \\
\hline Carbohydrate (g) & $62 \pm 28^{a}$ & $49 \pm 28^{b}$ & $48 \pm 29^{a}$ & $<0.01$ \\
\hline (\% of daily carbohydrate intake) & 30 & 28 & 28 & \\
\hline (\% of daily fat intake) & 38 & 37 & 35 & \\
\hline
\end{tabular}

a,b Means with different superscript letters differ significantly.

\section{Methodological considerations}

Results from studies of self-reported energy intake have to be interpreted with caution. Underestimation of food and nutrient intake is a generally recognized problem in food surveys (21), and has been estimated to amount to $20 \%$ of the energy intake (22). However, adding $20 \%$ to the mean energy intake of the groups in the present study would not raise the cooking and part-cooking groups to the reference values. It has been suggested that validation of dietary intake data could be performed by calculating the quotient between the reported energy intake $\left(\mathrm{EI}_{\mathrm{rep}}\right)$ and an estimation of the basal metabolic rate $\left(\mathrm{BMR}_{\mathrm{est}}\right)(21)$. The low $\mathrm{EI}_{\text {rep }} / \mathrm{BMR}_{\text {est }}$ could partly be explained by the fact that all participating women were included and no cut-off limit was used. Furthermore, the present study comprised older women with chronic diseases that may give rise to problems with food intake and meals, and therefore poor nutritional intake could be expected among several of the women. The use of a cut-off limit for women with PD and RA is not without problems, since these diseases affect metabolism (5). In addition, many lose weight after stroke, and do not have a stable weight. According to Hambraeus (23), weight stability is a necessary condition for the calculation of $\mathrm{EI}_{\mathrm{rep}} / \mathrm{BMR}_{\mathrm{est}}$. For the cooking group, the reference value for energy intake was estimated as $8.8 \mathrm{MJ}$. This value may be too high for the present group of older women who are not physically active. In SNR, reference values are $8.2-8.3 \mathrm{MJ} \mathrm{day}^{-1}$.

The $24 \mathrm{~h}$ recall is a "true recall of distinct, discrete events in the very recent past" $(24$, p. 57). Thus, it was judged to be a suitable method, since the ability to remember was ascertained in the telephone call before inclusion. The performance of the interviews in the homes of the women was supposed to facilitate accurate recall of food intake. Another advantage was that the researcher could check the sizes of cups and glasses, which may have enhanced the validity of the intake data. The $24 \mathrm{~h}$ recalls are based on two non-consecutive days of food intake, which entails a risk for distortion of results concerning nutrients that occur in abundance in food items that are rarely consumed. This method is not representative at the individual level, and it is therefore impossible to give a reliable picture for any of the presented nutrients.

All women were selected primarily to take part in a qualitative study and this may have diminished the external validity of the results (25), since those willing to talk about food dominated the sample. However, the majority $(71 \%)$ of the disabled women participated in this study. Furthermore, the inclusion rate was lowest among women with RA who were invited by a person outside the project. It is impossible to determine whether or how this has influenced the results. The women with RA had a wide range of symptoms, as did the women in the other groups. The main reasons for not participating in all groups were tiredness and problems related to illness. This suggests that women with these diagnoses living at home may have more problems than were documented in the present sample.

In the part-cooking group, 16 of 31 of the women had RA (Table 2). They wanted to be independent, were rather ingenious in handling their disability and struggled hard to be self-managing (Gustafsson et al., in press). However, since in a study of women with different diagnoses within part 2 of the MENEW project, women with RA did not have the lowest energy intake (Andersson et al., in press), it is unlikely that the low intake in the part-cooking group is primarily due to the diagnosis per se.

\section{Conclusions}

Energy intake was below reference values for all three groups, and tended to be lower for the disabled women as categorized on the basis of interviews and field notes. However, even though there may be 
underreporting, it is likely that diseases such as stroke, PD and RA contributed to the low energy intakes. The total number of meals was similar in the three groups, and hot meals contributed substantially to the total daily energy intake. The energy content of hot meals tended to be lower for disabled women in the part-cooking and no-cooking groups. If the total energy intake of these groups is constantly low, the women are at risk for poor nutrition. Hot meals need to be complemented by nutritious snacks.

\section{Acknowledgements}

This study was supported financially by the Swedish Foundation for Health Care Sciences and Allergy Research. We thank the staff at the Akademiska Hospital, Uppsala, for help with inclusion procedures, and Karin Norhamn and Katarina Virhammar for coding and entering the nutrient data.

\section{References}

1. Wylie C, Copeman J, Kirk L: Health and social factors affecting the food choice and nutritional intake of elderly people with restricted mobility. J Hum Nutr Diet 1999;12:375-80.

2. Rothenberg E, Bosaeus I, Steen B: Intake of energy, nutrients and food items in an urban elderly population. Aging Clin Exp Res 1993;5:105-16.

3. Sidenvall B, Lennernäs MA-C, Ek A-C: Elderly patient's meal patterns - a retrospective study. J Hum Nutr Diet 1996;9:263-72.

4. Larsson G, Unosson M, Ek A-C, Nilsson L, Thorslund S, Bjurulf P: Effects of dietary supplement on nutritional status and clinical outcome in 501 geriatric patients - a randomised study. Clin Nutr 1990;9:179-84.

5. Morley J: Anorexia of aging: physiologic and pathologic. Am J Clin Nutr 1997;66:760-73.

6. Nordenskiöld U. Daily activities in women with rheumatoid arthritis. Aspects of patient education, assistive devices and methods for disability and impairment assessment. Scand J Rehab Med 1997;(Suppl 37): $1-71$.

7. Andersson I, Sidenvall B: Case studies of food shopping, cooking and eating habits in older women with Parkinson's disease. J Adv Nurs 2001;35:69-78.

8. Westergren A, Ohlsson O, Hallberg I: Eating difficulties, complications and nursing interventions during a period of three months after a stroke. J Adv Nurs 2001;3 5:416-26.

9. Sidenvall B, Nydahl M, Fjellström C: Managing food shopping and cooking: the experience of older Swedish women. Ageing Soc 2001;21:151-68.
10. Schlettwein-Gsell D, Decarli B, De Groot L: Meal patterns in the SENECA study of nutrition and the elderly in Europe: assessment method and preliminary results on the role of the midday meal. Appetite 1999;32:15-22.

11. Bruce Å. Måltiden och måltidsordningen (Meals and meal pattern). Forskningsrådsnämnden 1991;5-7. (In Swedish.)

12. Sidenvall B, Fjellström C, Andersson J, Gustafsson K, Nygren U, Nydahl M: Reasons among older Swedish women of not participating in a food survey. Eur J Clin Nutr 2002;56:1-7.

13. Gibson R. Principles of nutritional assessment. Oxford: Oxford University Press, 1990.

14. NNR. Nordic Nutrition Recommendations, 3rd edn. Köpenhamn: Nordic Council of Ministers, 1996.

15. SLV Vikttabeller för livsmedel och maträtter. Uppsala: Swedish National Food Administration, 1992. (In Swedish.)

16. SNR. Swedish Nutrition Recommendations, 3rd edn. Vår föda 1997;2:8-14.

17. Black A: Critical evaluation of energy intake using the Goldberg cut-off for energy intake: basal metabolic rate. A practical guide to its calculation, use and limitations. Int J Obes 2000;24:1119-30.

18. Amorim Cruz J, Moreiras O, Brzozowska A. Longitudinal changes in the intake of vitamins and minerals of elderly Europeans. Eur J Clin Nutr 1996; 50 (Suppl 2): $77-85$.

19. Sonn U, Rothenberg E, Steen B: Dietary intake and functional ability between 70 and 76 years of age. Aging (Milan) 1998;10:324-31.

20. Morley J: Nutrition and the older female: a review. J Am Coll Nutr 1993;12:337-43.

21. Black A: The sensitivity and specificity of the Goldberg cut-off for EI: BMR for identifying diet reports of poor validity. Eur J Clin Nutr 2000;54:395-404.

22. Tomoyasu NJ, Toth MJ, Poehlman ET: Misreporting of total energy intake in older men and women. $J$ Geriatr Soc 1999;47:710-5.

23. Hambraeus L: Dietary assessment: how to validate primary data before conclusion can be drawn. Scand J Nutr/Näringsforskning 1998;42:66-8.

24. Wirfält E: Cognitive aspects of dietary assessment. Scand J Nutr/Näringsforskning 1998;42:56-9.

25. Kazdin A. Research design in clinical psychology, 3rd edn. Boston, MA: Allyn and Bacon, 1998.

Kerstin Gustafsson

Department of Public Health and Caring Sciences,

Uppsala University, Uppsala Science Park,

SE-75 I 83 Uppsala, Sweden.

E-mail: Kerstin.Gustafsson@pubcare.uu.se 